\title{
Produção de fitomassa e extração de macronutrientes por plantas de cobertura cultivadas na estação seca
}

\author{
Ana Lúcia SCAVAZZA ${ }^{1}$, Marcio Roberto SOARES ${ }^{1,2^{*}}$, José Carlos CASAGRANDE ${ }^{1,2}$, \\ Simone Daniela Sartorio de MEDEIROS ${ }^{3}$, Paulo Henrique Pizzi DE SANTI ${ }^{2}$
}

\begin{abstract}
${ }^{1}$ Programa de Pós-Graduação em Agricultura e Ambiente, Universidade Federal de São Carlos, Araras, SP, Brasil.
${ }^{2}$ Departamento de Recursos Naturais e Proteção Ambiental, Universidade Federal de São Carlos, Araras, SP, Brasil. ${ }^{3}$ Departamento de Tecnologia Agroindustrial e Socioeconomia Rural, Universidade Federal de São Carlos, Araras, SP, Brasil. *E-mail:mrsoares@cca.ufscar.br
\end{abstract}

Recebido em setembro/2017; Aceito em agosto/2018.

RESUMO: Na região centro-sul do Estado de São Paulo, informações sobre a adaptabilidade de plantas de cobertura cultivadas na estação seca são escassas. Objetivou-se com este estudo investigar a produção de fitomassa e extração de macronutrientes em plantas de cobertura durante a estação seca, em um Latossolo Vermelho distrófico, no município de Araras-SP. O delineamento foi em blocos ao acaso, com cinco tratamentos, correspondendo a espécies, em seis blocos. Na entressafra de milho 2015/2016, foram cultivadas: crotalária-spectabilis (Crotalaria spectabilis Roth.), feijão-guandu (Cajanus cajan L.), feijão-de-porco (Canavalia ensiformes L.), mucuna-preta (Stilozobium aterrimum Piper et Tray) e milheto (Pennisetum glaucum L.). O milheto foi a espécie que produziu mais fitomassa seca (acima de $8 \mathrm{t} \mathrm{ha}^{-1}$ ) e a que mais extraiu macronutrientes $\left(185 ; 10 ; 106 ; 42 ; 18\right.$ e $8 \mathrm{~kg} \mathrm{ha}^{-1}$ de N, P, K, Ca, Mg e S, respectivamente), apresentando relação $\mathrm{C} / \mathrm{N}$ inferior a 25 , sugerindo que seus resíduos sofreriam uma rápida decomposição e mineralização.A análise de agrupamento indicou que o feijão-guandu obteve desempenho semelhante ao do milheto. Crotaláriaspectabilis apresentou a menor fitomassa seca e extraiu menor quantidade de macronutrientes. Neste estudo, milheto e feijão-guandu foram as espécies que mais contribuíram para cobertura do solo e para a reciclagem de nutrientes na estação seca.

Palavras-chave: biomassa, nutrição, relação $\mathrm{C} / \mathrm{N}$, safrinha.

\section{Biomass production and nutrient accumulation by cover crops cultivated in the dry season}

\begin{abstract}
In the south-central region of the State of São Paulo, data on the adaptability of cover crops grown in the dry season are insuficient. The objective of this study was to investigate the biomass production and extraction of macronutrients in cover crops during the dry season, in a Oxysoil (LatossoloVermelho), in the city of Araras-SP. The design was in randomized blocks, with five treatments, corresponding to species in six blocks. In the maize off-season 2015/2016, were cultivated: crotalaria spectabilis (Crotalaria spectabilis Roth.), pigeon pea (Cajanus cajan L.), pig bean (Canavalia ensiformes L.), velvet bean (Stilozobium aterrimum Piper et Tray) and millet (Pennisetum glaucum L.). Millet was the species that produced the highest dry matter average (above 8 tons ha $\left.^{-1}\right)$ and the one that most extracted macronutrients $(185 ; 10 ; 106 ; 42 ; 18$ and 8 $\mathrm{Kg} \mathrm{ha}^{-1}$ of $\mathrm{N}, \mathrm{P}, \mathrm{K}, \mathrm{Ca}, \mathrm{Mg}$ and $\mathrm{S}$, respectively), showing a $\mathrm{C} / \mathrm{N}$ ratio of less than 25 , suggesting that its residues would undergo rapid decomposition and mineralization. The clustering analysis indicated that the pigeon pea had similar performance to millet. Crotalaria-spectabilis presented the lowest dried biomass extracted a smaller amount of macronutrients. In this study, millet and pigeon pea were the species that contributed the most to cover the soil and to recycle nutrients in the dry season.
\end{abstract}

Keywords: biomass, nutrition, $\mathrm{C} / \mathrm{N}$ ratio, off-season.

\section{INTRODUÇ̃̃O}

O sistema de plantio direto na palha tornou-se importante técnica para recuperação da capacidade produtiva de solos manejados convencionalmente e de áreas degradadas (GARCIA et al., 2014). O sucesso desse sistema está relacionado a fatores como a quantidade e a qualidade de resíduo vegetal depositado sobre o solo (TORRES et al., 2008). Há benefícios decorrentes do cultivo de plantas de cobertura nas propriedades do solo e no rendimento das culturas, por meio da produção de fitomassa, extração e liberação de nutrientes pela decomposição da palhada (BOER et al., 2007).
A rotação de culturas durante o período de entressafra, geralmente no inverno, é recomendável em sistemas que visem à diversificação das atividades agrícolas, sendo estratégia importante para melhoria da qualidade do solo, minimizando os problemas do monocultivo (SOUZA et al., 2008). As plantas de cobertura, quando semeadas na entressafra, apresentam capacidade de absorver nutrientes em camadas subsuperficiais e de posteriormente liberá-los nas camadas superficiais do solo, por meio da decomposição e da mineralização de seus resíduos, o que pode contribuir para diminuir a quantidade de fertilizantes industriais nas culturas anuais semeadas em sucessão (CESAR et al., 2011). 
A maior parte dos estudos sobre o comportamento de plantas de cobertura na entressafra concentra-se na região do Cerrado onde, entre os meses de abril e setembro, as condições climáticas são de reduzidas precipitações e de elevada temperatura, o que dificulta o estabelecimento destas espécies (PACHECO et al., 2008). O uso de plantas de cobertura semeadas em safrinha no Cerrado tem sido praticado na tentativa de reduzir a erosão, incrementar o teor de matéria orgânica e proporcionar a ciclagem de nutrientes após a colheita da cultura anual (SOUZA et al., 2008; PACHECO et al., 2012).

A formação de palhada para o sistema de plantio direto depende da capacidade da planta de cobertura em produzir elevadas quantidades de fitomassa seca em condições de déficit hídrico e também apresentar resistência quanto à decomposição durante a entressafra, que se relaciona à proporção entre carbono e nitrogênio (relação $\mathrm{C} / \mathrm{N}$ ) do material (CRUSCIOL et al., 2005). Assim, resíduos com relação $\mathrm{C} / \mathrm{N}$ maiores do que 25 formam coberturas mais estáveis no solo, enquanto os menores que 25 decompõem-se mais rapidamente (FABIAN, 2009). A taxa de decomposição dos resíduos vegetais no Cerrado pode ser até dez vezes maior do que em regiões de clima temperado (COSTA et al., 2014).

Os resíduos das poáceas promovem a melhoria do solo, por possuírem maior conteúdo de lignina, possibilitando aumento em ácidos carboxílicos e ácidos húmicos, favorecendo a estruturação e a estabilidade dos agregados do solo (CARVALHO et al., 2008). As leguminosas, por fixarem nitrogênio atmosférico, elevam a disponibilidade deste nutriente no solo. No entanto, são pouco utilizadas como plantas de cobertura em sistema de plantio direto em função do desenvolvimento inicial lento e alta taxa de decomposição de seus resíduos, desprotegendo o solo rapidamente (TEODORO et al., 2011; BORGES et al., 2015). Porém, resultados positivos têm sido alcançados com a semeadura de leguminosas após a cultura principal (CRUSCIOL; SORATO, 2009). Especificamente na região centro-sul do Estado de São Paulo, informações sobre a adaptabilidade de plantas de cobertura em condições de safrinha são escassos, sendo necessários estudos para se conhecer o desempenho de produção de fitomassa e ciclagem de nutrientes destas espécies (BORGES et al., 2015).

Nesta pesquisa, testou-se a hipótese de que plantas de cobertura, quando cultivadas em período de escassez hídrica e alta temperatura, diferem quanto à produção de palhada e extração de nutrientes do solo. Para isso, comparamos a produção de fitomassa e a extração de macronutrientes nas espécies de cobertura durante a estação seca, em um Latossolo Vermelho distrófico, no município de Araras-SP.

\section{MATERIAL E MÉTODOS}

O estudo foi conduzido em área experimental do Centro de Ciências Agrárias da Universidade Federal de São Carlos, localizado no município de Araras-SP, nas coordenadas geográficas de $22^{\circ} 18^{\prime} \mathrm{S}$ e $47^{\circ} 23^{\prime} \mathrm{O}$, altitude de $690 \mathrm{~m}$, entre fevereiro e junho de 2016. O clima da região é classificado como Cwa, mesotérmico, com verões quentes e úmidos, e invernos secos. A precipitação anual média é de $1.430 \mathrm{~mm}$ e temperatura média anual de $21,45^{\circ} \mathrm{C}$ (PERES et al., 2010) (Figura 1).

O solo da área experimental é classificado como Latossolo Vermelho distrófico (EMBRAPA, 2013), com as seguintes características físico-químicas na camada de 0-20 $\mathrm{cm}: 550,290$ e $160 \mathrm{~g} \mathrm{~kg}^{-1}$ de argila, silte e areia, respectivamente; $\mathrm{pH}\left(\mathrm{CaCl}_{2}\right)$ - 5,8; $\mathrm{P}$ (P resina) - $31 \mathrm{mg} \mathrm{dm}^{-3}$; $\mathrm{K}-6,8 \mathrm{mmol}_{\mathrm{c}} \mathrm{dm}^{-3} ; \mathrm{Ca}-9 \mathrm{mmol}_{\mathrm{c}} \mathrm{dm}^{-3} ; \mathrm{Mg}-4,0 \mathrm{mmol}_{\mathrm{c}}$ $\mathrm{dm}^{-3} ; \mathrm{H}+\mathrm{Al}-28 \mathrm{mmol}_{\mathrm{c}} \mathrm{dm}^{-3}$; matéria orgânica - $28 \mathrm{~g} \mathrm{dm}^{-3}$; $\mathrm{CTC}_{\mathrm{t}}-48,2 \mathrm{mmol}_{\mathrm{c}} \mathrm{dm}^{-3} ; \mathrm{S}-28 \mathrm{mg} \mathrm{dm}^{-3}$; saturação por bases (V\%) - 42\%. As amostras foram analisadas conforme métodos descritos em Raij et al. (2001) e em EMBRAPA (1997).

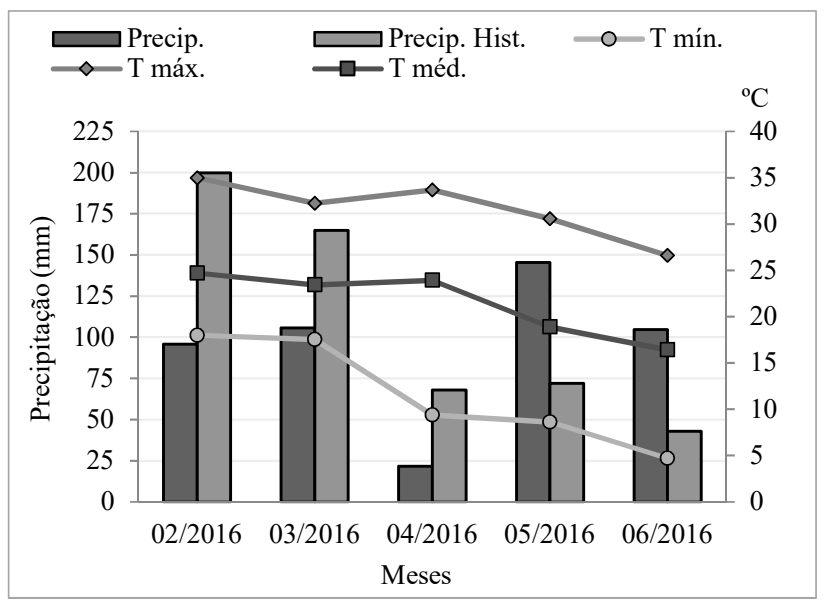

Figura 1. Informações climáticas do período experimental e precipitação histórica do munícipio de Araras-SP. Fonte: Dados climatológicos CCA/UFSCar (2016). Precip.= Precipitação; Precip. Hist. = Precipitação Histórica; $\mathrm{T}$. mín. $=$ Temperatura mínima; $\mathrm{T}$. máx.=Temperatura máxima; T. méd. $=$ Temperatura média.

Figure 1. Climatic information of the experimental period and historical precipitation of the city of Araras-SP. Source: Climatic data CCA/UFSCar (2016). Precip. = Precipitation; Precip. Hist. $=$ Historical Precipitation; T. mín $=$ Minimum temperature; $\mathrm{T}$ máx. $=$ Maximum temperature; T. méd.= average temperature.

A área foi cultivada com rotação milho-pousio em sistema convencional na safra 2014/2015. A semeadura de plantas de cobertura ocorreu no final de fevereiro de 2016, com seis blocos estabelecidos ao acaso. Os tratamentos foram constituídos por cinco espécies de cobertura: crotaláriaspectabilis (Crotalaria spectabilis Roth.); feijão-guandu (Cajanus cajan L.); feijão-de-porco (Canavalia ensiformes L.); mucuna-preta (Stilozobium aterrimum Piper et Tray) e milheto (Pennisetum glaucum L.), apresentados na Tabela 1. A área de cada parcela experimental foi de $30 \mathrm{~m}^{2}(3 \times 10 \mathrm{~m})$.

Tabela 1. Densidade de semeadura, espaçamento e ciclo das plantas de cobertura por ocasião de florescimento pleno.

Table 1. Seeding density, spacing and cycle of cover crops at full flowering.

\begin{tabular}{lclcc}
\hline Espécie & $\begin{array}{c}\text { Sementes } \\
\mathrm{m}^{-1}\end{array}$ & $\begin{array}{c}\text { Família } \\
\text { Botânica }\end{array}$ & $\begin{array}{c}\text { Esp. } \\
(\mathrm{m})\end{array}$ & $\begin{array}{c}\text { Ciclo Flor. } \\
\text { (dias) }\end{array}$ \\
\hline Crotalária-spec. & 30 a 35 & Fabaceae & 0,5 & $90-120$ \\
Feijão-guandu & 18 a 20 & Fabaceae & 0,5 & $90-120$ \\
Feijão-de-porco & 4 a 5 & Fabaceae & 0,5 & $90-100$ \\
Milheto & 50 a 55 & Poaceae & 0,25 & $60-90$ \\
Mucuna-preta & 3 a 4 & Fabaceae & 0,5 & $120-150$ \\
\hline
\end{tabular}

spec.=spectabilis; Esp.=espaçamento de plantio em metros; Ciclo Flor.= ciclo até o florescimento. Fonte: Adaptado de Sodré Filho et al. (2004).

Após 100 dias da emergência das plantas de cobertura, no estádio de pleno florescimento, foi avaliada a fitomassa seca, com o uso de um quadrado de ferro (gabarito de 0,25 $\mathrm{m}^{2}$ ), com duas repetições por parcela, conforme proposto por 
Crusciol et al. (2005). Em seguida, as amostras foram submetidas à secagem em estufa com temperatura de $65^{\circ} \mathrm{C}$ por 72 horas e pesadas para determinação da fitomassa seca. Os materiais vegetais foram triturados em moinho tipo Willey (malha de $2 \mathrm{~mm}$ ) e submetidos à digestão sulfúrica, para extração de $\mathrm{N}$, e nítrico-perclórica, para a extração dos demais macronutrientes (EMBRAPA, 1997). A determinação analítica ocorreu por: $\mathrm{N}$ - semimicro-Kjeldahl; $\mathrm{P}$ colorimetria do metavanadato; $\mathrm{K}$ - fotometria de chama de emissão; $\mathrm{Ca}$ e $\mathrm{Mg}$ - espectrofotometria de absorção atômica); $\mathrm{S}$ - turbidimetria do sulfato de bário. Para a determinação da relação $\mathrm{C} / \mathrm{N}$, a concentração de carbono total nos tecidos vegetais foi quantificada por método colorimétrico (RAIJ et al., 2001).

Os resultados, apresentando distribuição normal, foram submetidos à análise de variância e, quando significativa, as médias dos tratamentos foram comparadas pelo teste de Tukey a 5\% de significância, com auxílio do programa R (R DEVELOPMENT CORE TEAM, 2017). Realizou-se a análise de agrupamento hierárquico, conforme método do vizinho mais próximo, de todo o conjunto amostral para agrupamento de plantas de coberturas com desempenho similares, usando-se a distância euclidiana, uma medida da dissimilaridade entre os tratamentos para identificar possíveis padrões entre as espécies quando estas são cultivadas na estação seca (CRUZ, 2006).

\section{RESULTADOS}

As plantas de cobertura apresentaram diferenças significativas quanto à produção de fitomassa seca, extração de nutrientes e relação $\mathrm{C} / \mathrm{N}$ (Tabela 2). $\mathrm{O}$ milheto apresentou a maior produção de fitomassa seca, com média superior a $8 \mathrm{t}$ ha $^{-1}$ (Figura 2A). Considerando que a quantidade adequada para boa cobertura do solo é de $6 \mathrm{t} \mathrm{ha}^{-1}$ (TEODORO et al., 2011), apenas o milheto, em condições de entressafra, produziu fitomassa seca acima desta meta.

A resistência à decomposição, representada pela relação $\mathrm{C} / \mathrm{N}$, fator importante para a cobertura e disponibilidade de $\mathrm{N}$ no solo, foi superior no tratamento cultivado com mucunapreta, embora esta espécie tenha produzido menor fitomassa seca (Figura 2B). Esta espécie foi a única a exibir relação $\mathrm{C} / \mathrm{N}$ acima de 25 , sugerindo uma cobertura do solo mais estável e com maior equilíbrio entre os processos de mineralização e de imobilização de N (CRUSCIOL et al., 2005).

Tabela 2. Resumo da Análise de Variância (ANOVA-Teste F) e coeficiente de variação das características experimentais de cinco espécies de cobertura cultivadas em estação seca em Araras-SP, ano de 2016.

Table 2. Summary of Analysis of Variance (ANOVA-Test F) and coefficient of variation of experimental characteristics of five cover crops cultivated in dry season in Araras-SP, 2016 year.

\begin{tabular}{|c|c|c|c|c|c|c|c|c|c|}
\hline \multicolumn{10}{|c|}{ ANOVA - Teste F } \\
\hline $\mathrm{FV}$ & $\mathrm{gl}$ & Fitomassa Seca & $\mathrm{N}$ & $\mathrm{P}$ & $\mathrm{K}$ & $\mathrm{Ca}$ & $\mathrm{Mg}$ & $\mathrm{S}$ & $\mathrm{C} / \mathrm{N}$ \\
\hline Bloco & 5 & $0,90^{\mathrm{ns}}$ & $0,83^{\mathrm{ns}}$ & $2,24^{\mathrm{ns}}$ & $1,04^{\mathrm{ns}}$ & $0,90^{\mathrm{ns}}$ & $0,74^{\mathrm{ns}}$ & $0,33^{\mathrm{ns}}$ & $0,97^{\mathrm{ns}}$ \\
\hline Plantas de cobertura & 4 & $17,82^{* *}$ & $15,45^{* *}$ & $3,29^{*}$ & $5,04^{* *}$ & $16,08^{* *}$ & $7,72^{* *}$ & $5,08^{* *}$ & $8,50^{* *}$ \\
\hline $\mathrm{CV} \%$ & & $24,62 \%$ & $30,16 \%$ & $38,86 \%$ & $50,28 \%$ & $47,02 \%$ & $39,70 \%$ & $48,37 \%$ & $23,69 \%$ \\
\hline
\end{tabular}

FV: fonte de variação; gl: grau de liberdade; ${ }^{\text {ns: }}$, não significativo; ${ }^{*}$ significativo a $5 \%$ de probabilidade pelo teste $\mathrm{F} ;{ }^{* *}$ significativo a $1 \%$ de probabilidade pelo teste F.

O milheto foi a espécie que mais extraiu macronutrientes (Tabela 3). Mesmo não apresentando maior teor de todos os nutrientes em seus tecidos, o milheto apresentou maior extração em razão da maior produção de fitomassa seca por área. O feijão-de-porco e o feijão-guandu demonstraram extração de nitrogênio estatisticamente igual ao do milheto.
Dentre todos os nutrientes, $\mathrm{N}$ e $\mathrm{K}$ apresentaram estimativa da média com maior variabilidade. De forma geral, foi observado extração de macronutrientes pelas plantas de cobertura conforme o padrão $\mathrm{N}>\mathrm{K}>\mathrm{Ca}>\mathrm{Mg}>\mathrm{P}>\mathrm{S}$, com exceção da mucuna-preta, em que a ordem de extração foi de $\mathrm{N}>\mathrm{K}>\mathrm{P}>\mathrm{Mg}>\mathrm{Ca}>\mathrm{S}$.

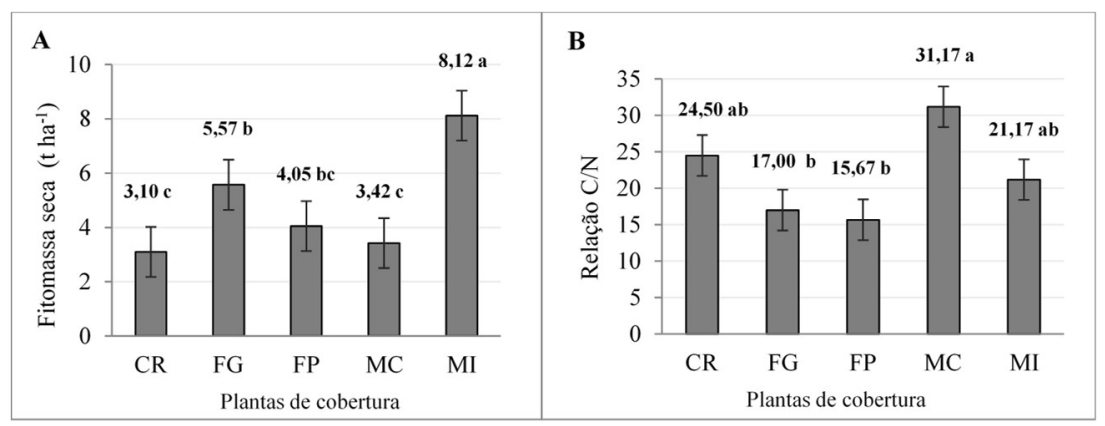

Figura 2. Valores médios de produção de fitomassa seca (A) e de relação $\mathrm{C} / \mathrm{N}$ (B) de plantas de cobertura cultivadas em estação seca em Araras-SP, ano de 2016. Médias com letras iguais não diferem pelo teste de Tukey a 5\% de probabilidade. Linhas verticais indicam a variação do erro padrão da média dos tratamentos. CR: crotalária-spectabilis; FG: feijão-guandu; FP: feijão-de-porco; MC: mucuna-preta; MI: milheto. Figure 2. Average values of dry matter (A) and $\mathrm{C} / \mathrm{N}$ ratio (B) of cover crops grown in dry season in Araras-SP, 2016 year. Means with equal letters do not differ by Tukey's test to $5 \%$ probability. Vertical lines indicate the variation of the standard error of the mean of the treatments. CR: crotalaria-spectabilis; FG: pigeon pea; PF: pig bean; MC: velvet bean; MI: millet.

A análise multivariada de todas as características avaliadas das plantas de cobertura está representada no dendrograma da Figura 3, indicando a divisão em grupos de tratamentos com plantas de cobertura com maior ou menor distância euclidiana, ou seja, menos ou mais semelhantes. Crotalária e mucuna-preta agruparam-se separadamente do 
feijão-de-porco, feijão-guandu e milheto. Neste último grupo, feijão-guandu e milheto apresentaram maior semelhança entre si quando analisado todo o conjunto amostral.

Os resultados dos testes de comparação de médias (Figura 2, Tabela 3) mostraram que os valores médios do feijão- guandu e milheto foram estatisticamente equivalentes em todas as variáveis, com exceção da produção de fitomassa seca, corroborando com a interpretação do dendrograma, em que o desempenho destas duas espécies durante a estação seca foram semelhantes.

Tabela 3. Valores médios e erro padrão de macronutrientes acumulados na fitomassa seca de cinco plantas de cobertura do solo, durante estação seca no município de Araras-SP, ano de 2016.

Table 3. Average values and standard error of accumulated macronutrients in the dry biomasss of five ground cover crops, during dry season in the city of Araras-SP, 2016 year.

\begin{tabular}{lcccccc}
\multirow{2}{*}{ Tratamentos } & $\mathrm{N}$ & $\mathrm{P}$ & $\mathrm{K}$ & $\mathrm{Ca}$ & $\mathrm{Mg}$ & $\mathrm{S}$ \\
\cline { 2 - 7 } & & \multicolumn{5}{c}{$\mathrm{kg} \mathrm{ha}^{-1}$} \\
\hline Crotalária-spec. & $58,93 \pm 4,36 \mathrm{~b}$ & $5,72 \pm 0,53 \mathrm{ab}$ & $45,33 \pm 9,91 \mathrm{~b}$ & $17,53 \pm 1,57 \mathrm{~b}$ & $10,30 \pm 1,15 \mathrm{~b}$ & $2,60 \pm 0,85 \mathrm{~b}$ \\
Feijão-guandu & $162,62 \pm 15,97 \mathrm{a}$ & $7,96 \pm 1,26 \mathrm{ab}$ & $75,09 \pm 14,10 \mathrm{ab}$ & $53,62 \pm 9,40 \mathrm{a}$ & $12,23 \pm 1,56 \mathrm{ab}$ & $5,76 \pm 1,21 \mathrm{ab}$ \\
Feijão-de-porco & $135,46 \pm 17,09 \mathrm{a}$ & $5,21 \pm 0,71 \mathrm{~b}$ & $37,96 \pm 5,26 \mathrm{~b}$ & $16,50 \pm 1,86 \mathrm{~b}$ & $7,38 \pm 0,94 \mathrm{~b}$ & $4,20 \pm 1,12 \mathrm{ab}$ \\
Mucuna-preta & $60,19 \pm 11,10 \mathrm{~b}$ & $6,20 \pm 1,03 \mathrm{ab}$ & $44,96 \pm 6,54 \mathrm{~b}$ & $3,60 \pm 0,53 \mathrm{~b}$ & $5,43 \pm 0,66 \mathrm{~b}$ & $3,31 \pm 4,17 \mathrm{~b}$ \\
Milheto & $185,10 \pm 19,30 \mathrm{a}$ & $10,17 \pm 2,10 \mathrm{a}$ & $106,00 \pm 21,12 \mathrm{a}$ & $42,41 \pm 5,87 \mathrm{a}$ & $17,79 \pm 2,99 \mathrm{a}$ & $7,89 \pm 1,35 \mathrm{a}$ \\
\hline
\end{tabular}

Médias com letras iguais não diferem entre si pelo teste de Tukey a 5\% de significância. Spec. $=$ spectabilis

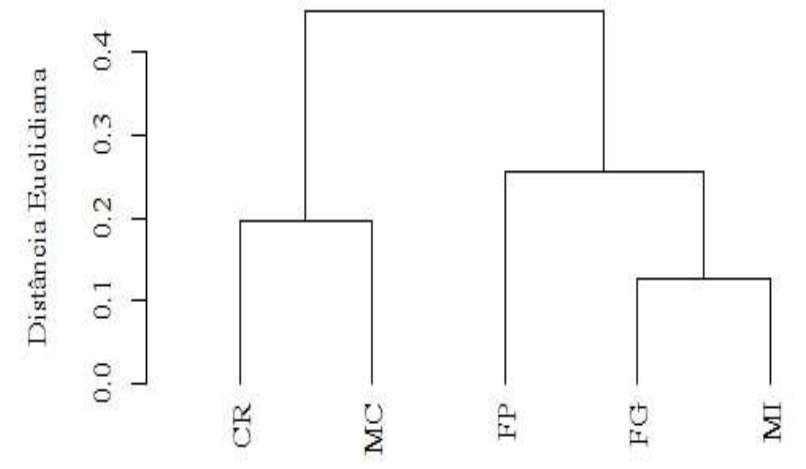

Plantas de cobertura

Figura 3. Dendrograma da análise de agrupamento de todas as características avaliadas das plantas de cobertura estudadas na estação seca no município de Araras-SP, ano de 2016. CR: crotaláriaspectabilis; FG: feijão-guandu; FP: feijão-de-porco; MC: mucuna-preta; MI: milheto.

Figure 3. Dendrogram of the cluster analysis of all characteristics evaluated from the cover crops studied in the dry season in the city of Araras-SP, 2016 year. CR: crotalaria-spectabilis; FG: pigeon pea; PF: pig bean; MC: velvet bean; MI: millet.

\section{DISCUSSÃO}

As condições climáticas durante o período experimental podem ter influenciado decisivamente nos resultados, principalmente pela escassez de chuvas no período inicial de desenvolvimento das plantas de cobertura (março e abril), que foi cerca de $45 \%$ menor do que a média histórica de precipitação para o munícipio de Araras-SP (Figura 1).

Pacheco et al. (2011) avaliaram a produção de fitomassa e a extração de nutrientes por milheto em Latossolo Vermelho distrófico, durante a entressafra de soja 2007/2008, em dois locais do Estado de Goiás. No município de Santo Antônio de Goiás, entre os meses de março e maio, as plantas de cobertura beneficiaram-se de uma precipitação em torno de $440 \mathrm{~mm}$, próxima a precipitação ocorrida neste experimento. Em Rio Verde, entre os meses de abril e junho, as espécies dispuseram de cerca de $180 \mathrm{~mm}$ de chuva. O milheto produziu acima de $8 \mathrm{t} \mathrm{ha}^{-1}$ de fitomassa seca em Santo Antônio de Goiás, enquanto em Rio Verde a produção máxima não ultrapassou $3,6 \mathrm{t} \mathrm{ha}^{-1}$. Em situação de déficit hídrico severo, com precipitação inferior a $70 \mathrm{~mm}$, Sodré Filho et al. (2004) avaliaram a fitomassa seca de sete plantas de cobertura em LatossoloVermelho-Amarelo, no município de Planaltina-DF. Nesta situação, milheto e feijão-guandu tiveram produção de fitomassa seca comprometida, não ultrapassando $2 \mathrm{t} \mathrm{ha}^{-1}$, demonstrando que a semeadura tardia e baixa disponibilidade hídrica afeta o desenvolvimento da maioria das plantas de cobertura.

Além disso, o baixo desempenho das leguminosas, principalmente da crotalária e do feijão-guandu, pode ser explicado pela sensibilidade à ação fotoperiódica, já que a semeadura tardia tende a diminuir a produção de matéria seca destas espécies (FERREIRA et al., 2013). Amabile et al. (2000) constataram que a semeadura no início de março em Senador Canedo-GO, reduziu a produção de fitomassa seca de Crotalaria juncea, Crotalaria ochroleuca e Cajanus cajan. A mucuna-preta não apresentou sensibilidade ao fotoperíodo e à diminuição da precipitação, produzindo cerca de $4 \mathrm{t} \mathrm{ha}^{-1}$ de fitomassa seca, tanto quando semeada em novembro quanto em março, resultado muito próximo ao obtido neste estudo, quando esta espécie foi semeada no final de fevereiro.

A relação $\mathrm{C} / \mathrm{N}$ das plantas de cobertura, sobretudo do milheto, foi inferior àquelas relatadas na literatura científica, situando-se entre 30 a 35 . Este fato pode ser explicado devido a maior extração de $\mathrm{N}$ pelo milheto (185 $\left.\mathrm{kg} \mathrm{ha}^{-1}\right)$ nas condições experimentais testadas, superior ao obtido por Pacheco et al. (2011), que totalizou $148 \mathrm{~kg} \mathrm{ha}^{-1}$ de N. A mucuna-preta, apesar de ser uma leguminosa, demonstrou alta relação $\mathrm{C} / \mathrm{N}$ (31), uma vez que para esta espécie o ideal situa-se entre 20 a 25 . Este resultado pode ter sido decorrente da baixa absorção de $\mathrm{N}$, pela interferência de algum fator biótico ou abiótico na fixação biológica de nitrogênio, como altas temperaturas do solo, estresse hídrico, presença de micro-organismos antagonistas, dentre outros (FAGAN et al., 2007; FERNANDES JÚNIOR; REIS, 2008).

A maioria dos trabalhos científicos que avaliaram a extração de nutrientes por plantas de cobertura no Cerrado foram realizados na estação chuvosa, época em que a absorção de nutrientes e produção de fitomassa seca é maior. $\mathrm{Na}$ estação seca, destacam-se estudos com milheto, feijãoguandu e mucuna-preta (BOER et al., 2007; PACHECO et al., 2011). Os resultados deste experimento, comparados com 
estes estudos mostraram que, com exceção do $\mathrm{N}$, todos os macronutrientes foram extraídos em menor quantidade, principalmente o $\mathrm{Ca}$ e $\mathrm{Mg}$, embora baixo teor de nutrientes no solo tenha sido observado apenas para o Mg (RAIJ, 2011). O milheto, conforme relatado por Crusciol; Sorato, (2009) foi capaz de acumular quantidades consideráveis de nutrientes em pequeno espaço de tempo, principalmente de $\mathrm{N}$ e $\mathrm{K}$, por ser uma espécie de rápido crescimento e ciclo curto.

Sugere-se para futuros experimentos a avaliação da produção de fitomassa, extração e liberação de nutrientes em condições de cultivo de verão e safrinha na região centro-sul do Estado de São Paulo, testando cultivo solteiro e consorciado destas e de outras plantas de coberturas.

\section{CONCLUSÕES}

O milheto (Pennisetum glaucum L.) é a planta de cobertura que produz maior quantidade de fitomassa seca e a que mais acumula macronutrientes, apresentando baixa relação $\mathrm{C} / \mathrm{N}$, sugerindo uma decomposição e mineralização mais rápida de sua palhada. A análise de agrupamentos de todo o conjunto amostral revela que há similaridade no desempenho entre o milheto e feijão-guandu, em condições de cultivo em estação seca.

\section{AGRADECIMENTOS}

Os autores agradecem à Piraí Sementes, Profa. Dra. Priscilla de Paula Loiola, ao Grupo de Estudos e Pesquisas em Fertilidade do Solo, Adubação e Nutrição de Plantas (GEFERT-UFSCar) e ao Laboratório de Fertilidade do Solo da Universidade Federal de São Carlos, campus Araras.

\section{REFERÊNCIAS}

AMABILE, R. F.; FANCELLI, A. L.; CARVALHO, A. M. Comportamento de espécies de adubos verdes em diferentes épocas de semeadura e espaçamentos na região dos Cerrados. Pesquisa Agropecuária Brasileira, Brasília, v. 35, n. 1, p. 47-54, jan. 2000. DOI: http://dx.doi.org/10.1590/S0100-204X2000000100007

BOER, C. A.; ASSIS, R. L.; SILVA, G. P.; BRAZ, A. J. B. P.; BARROSO, A. L. L.; CARGNELUTTI FILHO, A.; PIRES, F. R. Ciclagem de nutrientes por plantas de cobertura na entressafra em um solo de cerrado. Pesquisa Agropecuária Brasileira, Brasília, v. 42, n. 9, p. 12691276, 2007. DOI: http://dx.doi.org/10.1590/S0100204X2007000900008

BORGES, W. L. B.; FREITAS, R. S.; MATEUS, G. P.; SÁ, M. E.; ALVES, M. C. Plantas de cobertura para o noroeste do estado de São Paulo. Ciência Rural, Santa Maria, v. 45, n. 5, p. 799-805, mai. 2015. DOI: http://dx.doi.org/10.1590/0103-8478cr20131018

CARVALHO, A. M.; BUSTAMANTE, M. M. C.; SOUSA JUNIOR, J. G. A.; VIVALDI, L. J. Decomposição de resíduos vegetais em Latossolo sob cultivo de milho e plantas de cobertura. Revista Brasileira de Ciência do Solo, Viçosa, v. 32, n. esp., p.2831-2838, 2008. DOI: http://dx.doi.org/10.1590/S0100-06832008000700029

CESAR, N. Z.; GUERRA, J. G. M.; RIBEIRO, R. L. D.; URQUIAGA, S. S. C.; PADOVAN, M. P. Performance de adubos verdes cultivados em duas épocas do ano no Cerrado do Mato Grosso do Sul. Revista Brasileira de Agroecologia, Pelotas, v. 6, n. 2, p. 159-169, ago. 2011.
COSTA, N. R.; ANDREOTTI, M.; BUZETTI, S.; LOPES, K. S. M.; SANTOS, F. G.; PARIZ, C. M. Acúmulo de macronutrientes e decomposição da palhada de braquiárias em razão da adubação nitrogenada durante e após o consórcio com a cultura do milho. Revista Brasileira de Ciência do Solo, Viçosa, v. 38, n. 4, p. 1223-1233, jul./ago. 2014. DOI: http://dx.doi.org/10.1590/S0100-06832014000400019

CRUSCIOL, C. A. C.; COTTICA, R. L.; LIMA, E. V.; ANDREOTTI, M.; MORO, E.; MARCON, E. Persistência de palhada e liberação de nutrientes do nabo forrageiro no plantio direto. Pesquisa Agropecuária Brasileira, Brasília, v. 40, n. 2, p. 161-168, fev. 2005. DOI: 204X2005000200009

http://dx.doi.org/10.1590/S0100-

CRUSCIOL, C. A. C.; SORATTO, R. P. Nitrogen supply for cover crops and effects on peanut grown in succession under a no-till system. Agronomy Journal, Madison, v. 101, n. 1, p. 41-46, 2009. DOI: https://dx.doi.org/10.2134/agronj2008.0054

CRUZ, C. D. Programa Genes - Análise Multivariada e simulação. Viçosa: Editora UFV, 2006. 175p.

CCA/UFSCar_CENTRO DE CIÊNCIAS AGRÁRIĀS/UNIVERSIDADE FEDERAL DE SÃO CARLOS. DADOS CLIMATOLÓGICOS. Disponível em: $<$ https://www.cca.ufscar.br/servicos/dadosclimatologicos/>. Acesso em: 01 jul 2016.

EMBRAPA_EMPRESA BRASILEIRA DE PESQUISA AGROPECUÁRIA. Manual de métodos de análise de solo. 2. ed. Rio de Janeiro: Embrapa-CNPS, 1997. 212 p.

EMBRAPA_ EMPRESA BRASILEIRA DE PESQUISA AGROPECUÁRIA. Sistema Brasileiro de Classificação de Solos. 3 ed. Rio de Janeiro: Embrapa-CNPS, 2013. $412 \mathrm{p}$.

FABIAN, A. J. Plantas de cobertura: efeito nos atributos do solo e na produtividade de milho e soja em rotação. 2009. 83f. Tese (Doutorado em Agronomia-Produção Vegetal) - Universidade Estadual Paulista, Faculdade de Ciências Agrárias e Veterinárias, Jaboticabal, SP, 2009.

FAGAN, E. B.; MEDEIROS, S. L. P.; MANFRON, P. A.; CASSOROLI, D.; SIMON, J.; DOURADO NETO, D.; VAN LIER, Q. J.; SANTOS, O. S.; MULLER, L. Fisiologia da fixação biológica de nitrogênio em soja revisão. Revista da Faculdade de Zootecnia, Veterinária e Agronomia, Uruguaiana, v. 14, n. 1, p. 89106, 2007.

FERNANDES JÚNIOR, P. A.; REIS, V. M. Algumas limitações à fixação biológica de nitrogênio em leguminosas. Seropédica: Embrapa Agrobiologia, 2008. 33 p. (Documentos 252).

FERREIRA, E. P. B.; STONE, L. F.; DIDONET, A. D. Green manure species and sowing time effects on the agronomic performance of common bean. Agronomy Journal, Madison, v. 105, n. 6, p. 1721-1727, 2013. DOI: https://dx.doi.org/10.2134/agronj2012.0478

GARCIA, C. M. P.; ANDREOTTI, M.; TEIXEIRA FILHO, M. C. M.; LOPES, K. S.; BUZETTI, S. Decomposição da palhada de forrageiras em função da adubação nitrogenada após o consórcio com milho e produtividade da soja em sucessão. Bragantia, Campinas, v. 73, n. 2, p. 143-152, 2014.

DOI: 
PACHECO, L. P.; PIRES, F. R.; MONTEIRO, F. P.; PROCÓPIO, S. O.; ASSIS, R. L.; CARMO, M. L.; PETTER, F. A. Desempenho de plantas de cobertura em sobressemeadura na cultura da soja. Pesquisa Agropecuária Brasileira, Brasília, v. 43, n. 7, p. 815823, 2008. DOI: http://dx.doi.org/10.1590/S0100204X2008000700005

PACHECO, L. P.; LEANDRO, W. M.; MACHADO, P. L. O. A.; ASSIS, R. L. de; COBUCCI, T.; MADARI, B.E.; PETTER, F.A. Produção de fitomassa e acúmulo e liberação de nutrientes por plantas de cobertura na safrinha. Pesquisa Agropecuária Brasileira, Brasília, v. 46, n. 1, p. 17-25, 2011. DOI: http://dx.doi.org/10.1590/S0100-204X2011000100003

PACHECO, L. P.; MEDEIROS, M. M. S.; SILVA, R. F.; SOARES, L. S.; FONSECA, W. L.; PETTER, F. A.; ALCANTARA NETO, F.; FERNANDES, A. A.; SANTOS, G. Biomass and Nutrient Accumulation of Cover Crops in the Crop Off-season in Cerrado, in Goiás State, Brazil. Journal of Agricultural Science, Toronto, v. 4, n. 9, p. 209-216, 2012. DOI: https://dx.doi.org/10.5539/jas.v4n9p209

PERES, J. G.; BRUGNARO, C.; SOUZA C. F.; PAPINI D. H.; CRUGER F. F.; ROVEA R. J. P. Avaliação da produtividade de grãos e do consumo de água de seis cultivares de feijoeiro para plantio de inverno na região de Araras-SP. Irriga, Botucatu, v. 15, n. 3, p. 335-343, $\mathrm{jul} / \mathrm{set}$. 2010. https://doi.org/10.15809/irriga.2010v15n3p335

RAIJ, B. V.; ANDRADE, J. C.; CANTARELLA, H.; QUAGGIO, J. A. Análise química para avaliação da fertilidade de solos tropicais. Campinas: Instituto Agronômico, 2001. 285 p.
RAIJ, B.V. Fertilidade do solo e manejo de nutrientes. Piracicaba: International Plant Nutrition Institute, $2011.420 \mathrm{p}$.

R DEVELOPMENT CORE TEAM. R: A Language and environment for statistical computing. Vienna: $R$ Foundation for Statistical Computing. Disponível em: $<$ https://www.r-project.org/>. Acesso em: 01 jun 2017.

SODRÉ FILHO, J.; CARDOSO, A. N.; CARMORA, L. R.; CARVALHO, A. M. Fitomassa e cobertura do solo de culturas de sucessão ao milho na Região do Cerrado. Pesquisa Agropecuária Brasileira, Brasília, v. 39, n. 4, p. 327-334, abr. 2004. DOI: http://dx.doi.org/10.1590/S0100-204X2004000400005

SOUZA, E. D.; CARNEIRO, M. A. C.; BANYS, V. L. Fitomassa e acúmulo de nitrogênio em espécies vegetais de cobertura do solo para um Latossolo vermelho distroférrico de Cerrado. Acta ScientiarumAgronomy, Maringá, v. 30, n. 4, p. 525-531, 2008. DOI: http://dx.doi.org/10.4025/actasciagron.v30i4.5313

TEODORO, R. B.; OLIVEIRA, F. L.; SILVA, D. M. N.; FÁVERO, C.; QUARESMA, M. A. L. Aspectos agronômicos de leguminosas para adubação verde no Cerrado do Alto Vale do Jequitinhonha. Revista Brasileira de Ciência do Solo, Viçosa, v. 35, n. 2, p. 635-643, mar./abr. 2011. DOI: http://dx.doi.org/10.1590/S0100-06832011000200032

TORRES, J. L. R.; PEREIRA, M. G.; FABIAN, A. J. Produção de fitomassa por plantas de cobertura e mineralização de seus resíduos em plantio direto. Pesquisa Agropecuária Brasileira, Brasília, v. 43, n. 3, p. 421-428, mar. 2008. DOI: http://dx.doi.org/10.1590/S0100-204X2008000300018 